\title{
Biointerface Between ZIF-8 and Biomolecules and their Applications
}

\author{
Hani Nasser Abdelhamid 1,* \\ 1 Advanced Multifunctional Materials Laboratory, Department of Chemistry, Assiut University, Assiut, 71516, Egypt \\ * Correspondence: hany.abdelhamid@aun.edu.eg; chemist.hani@yahoo.com;
}

Scopus Author ID 55370888300

Received: 21.06.2020; Revised: 17.07.2020; Accepted: 18.07.2020; Published: 22.07.2020

\begin{abstract}
This review summarized the recent progress of biointerface between zeolitic imidazolate frameworks (ZIF-8) and biological species such as protein, peptides, viruses, cells, and tissues. ZIF-8 has been widely conjugated with bio-entities offering remarkable loading capacity, high chemical stability in physiological environments, and tunable drug release properties. There are several methods to encapsulate biological species into ZIF-8. The synthesis methods such as one-pot synthesis and postsynthetic modification are widely used for the conjugation of biological species and ZIF- 8 . The biointerface interactions between the biomolecules and ZIF-8 precursors enhanced the synthesis procedure and improved the yield and the properties of the final products. Two enzymes and hybrid conjugation of enzyme and a nanoparticle were also reported. These combinations offered dual functions and provided extra properties such as simple separation of the materials after uses. A brief discussion of the applications of ZIF-8 biocomposite was also covered. This review allowed the readers to acquire insights into the importance of ZIF-8 for the immobilization of biomolecules for biomedicine.
\end{abstract}

Keywords: Zeolitic imidazolate frameworks; Metal-organic frameworks; Biomimetic; Enzyme; Biocomposites.

(C) 2020 by the authors. This article is an open-access article distributed under the terms and conditions of the Creative Commons Attribution (CC BY) license (https://creativecommons.org/licenses/by/4.0/).

\section{Introduction}

Metal-organic frameworks (MOFs), porous coordination polymers (PCPs), or porous coordination networks (PCNs) are hybrid porous materials [1-4]. They have large surface areas and tunable pore sizes [1-5]. Thus, they have advanced several applications, including adsorption [6,7], sensing [8-11], self-cleaning textiles [12], laser desorption/ionization mass spectrometry [13-18], and catalysis [19-21]. MOFs exhibit activity as enzyme [22]. MOFs improved biomedical applications. MOFs- biomolecule conjugation can also be defined as metal-biomolecule frameworks (MBioFs) [23]. Biocomposite of MOF and biological species such as proteins, viruses, living yeast cells, and bacteria were reported [24-27]. The encapsulation of biomolecules such as enzymes into MOFs can be used for several applications, including single-enzymatic biofuel cell-based self-powered biosensors [28].

Zeolitic imidazolate frameworks (ZIFs) is a subclass of MOFs with exceptionally high thermal and chemical stability [29]. Among the large number of ZIFs, ZIF-8 has been widely reported. ZIF-8 consists of zinc as a metal node and 2-methylimidazole (HmIm) as a linker [30-34]. ZIF-8 was applied for drug delivery [35-37], gene delivery [38-40], hydrogen production [41,42], dye sensitizing solar cells [43], carbon dioxide adsorption [44,45], and biosensing [46]. Three-dimensional (3D) ZIF-8 is one of the most widely explored MOFs for 
hosting bioentities. ZIF-8 offers several advantages, including pH-responsive dissolution, which provided on-demand drug release [47]. ZIF-8 composite microcarrier (MC) was reported for human mesenchymal stem cells (hMSCs) adhesion and proliferation [48].

This review discussed the biointerface between biomolecules and ZIF-8. The synthesis of biomolecules-ZIF-8 biocomposite is summarized. The biomolecules can be used as a directing agent, ensuring fast synthesis with tunable pore sizes. They also facilitated the encapsulation and improved the yields.

\section{Biomolecules as directing agents for the synthesis: biomimetic mineralization}

There are several methods for the synthesis of ZIF-8. Solvothermal synthesis of ZIF-8 was reported [29]. However, the one-pot synthesis was conducted at room temperature in water [35-44]. This method circumvents previously reported limitations, such as multistep procedure, and the need for additives and organic solvents. It is also suitable for thermal labile species such as protein, virus, and bacteria cells.

ZIF-8 was synthesized using common traditional synthesis methods for crystal formation and engineering. ZIF-8 was synthesized via biomimetic mineralization methods. Biomimetic mineralization approaches use a biomolecule as directing agents. Thus, the final products are usually biocomposites containing both ZIF-8 and biomolecules, such as proteins/peptides, enzymes, cells, and DNA. Typically, an aqueous solution containing a biomolecule together with 2-methylimidazole $(\mathrm{HmIm})$ or Zinc salt is mixed with the complementary reagent (e.g., Hmim or Zinc salt) at room temperature. The mixture was stirred, leading to a milky solution due to the material's formation. The particles are separated using centrifugation or other separation methods.

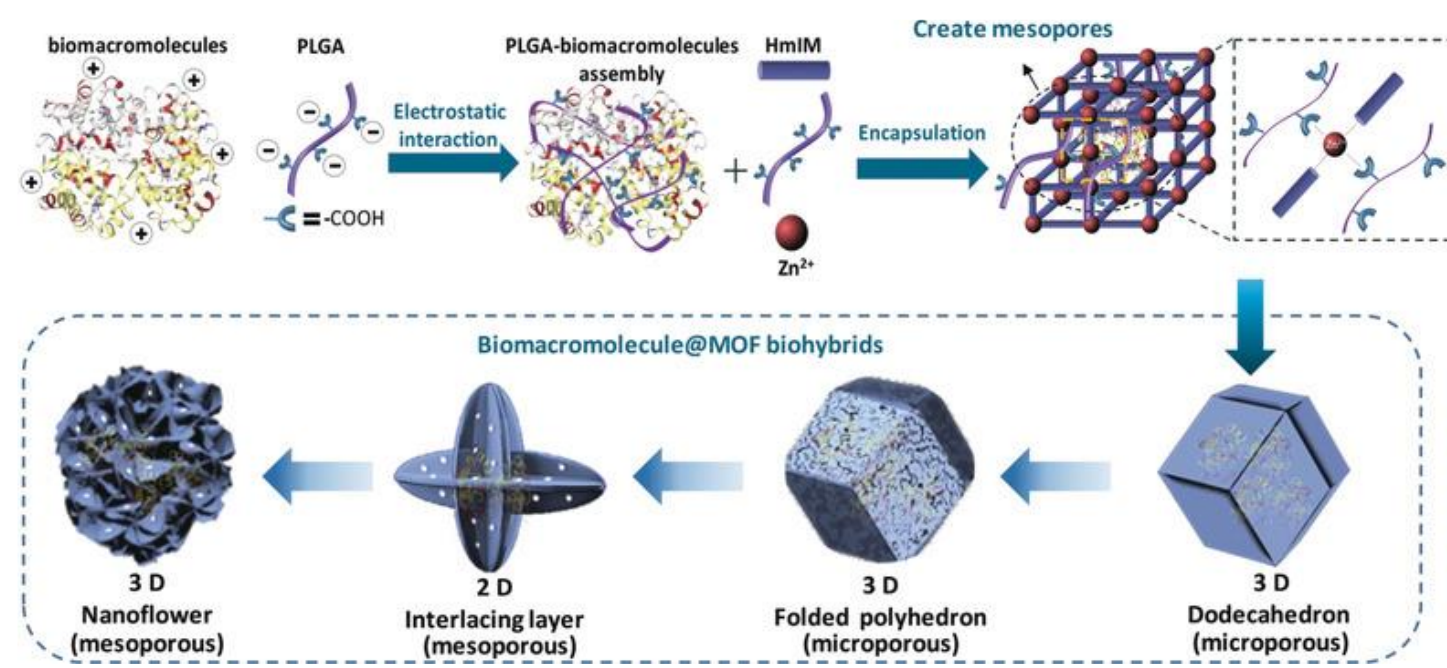

Figure 1. The in-situ encapsulation of biomacromolecules within a MOF using a PLGA modulator [51]. Reprinted with permission from Embedding Functional Biomacromolecules within Peptide-Directed MetalOrganic Framework (MOF) Nanoarchitectures Enables Activity Enhancement. Copyright (2020) Wiley-VCH Verlag GmbH \& Co. KGaA, Weinheim.

Several parameters affect the morphology and structure of the final products. The affinity between zinc ions and the target biomolecules promotes the biomimetic process and controlling the morphology of the final products. The multivalent nature of complicated species such as tobacco mosaic virus (TMV, a tubular RNA plant with a size of $300 \mathrm{~nm} \times 18 \mathrm{~nm}$ containing 2130 identical coat proteins arranged helically around a $4 \mathrm{~nm}$ central pore of viral RNA) enabled concentration of zinc ions leading to the increasing of the local concentration of 
active sites before their immobilization [49]. DNA cross-linking agents enhanced the growth of ZIF-8 on the surface of magnetic particles (MPs)[50].

Protein and peptides can be used as an effective directing agent for the synthesis of ZIF8 [51]. Authors synthesized ZIF-8 biohybrid with different shapes from different 3D microporous architectures into a 2D mesoporous spindle-shaped MOFs (2D MSMOFs) using $\gamma$-poly-1 -glutamic acid (PLGA), a peptide, as the modulator (Figure 1) [51]. Furthermore, the activity of the entrapped biomolecules has been significantly increased [51].

ZIF-8 offers an effective model for viral vector via the protection of the encapsulated protein against denaturing conditions [49]. ZIF-8 protein biocomposites are promising candidates for proteinaceous drugs with high biocompatibility and controlling the release/adsorption of therapeutic agents in vivo.

\subsection{Protein@ZIF-8.}

Protein was used for the biomineralization of ZIF-8. Several parameters were reported for protein-mediated ZIF-8 biomineralization [52]. A library of peptides and proteins with different charges was investigated to understand the role of these reagents in the biomineralization [52]. Protein with negative charged exhibited high affinity against the precursors of ZIF-8, especially zinc ions due to the electrostatic attraction. Thus, the interactions eventually lead to induce the formation of ZIF crystals. On the other side, the biomineralization process of cationic peptides ( $\mathrm{pI}>\mathrm{pH}$ 7.5) showed the formation of a diamond phase of zinc imidazolate (dia- $\left.\mathrm{Zn}(\mathrm{HmIm})_{2}\right)$ [52]. The encapsulation efficiencies of bovine serum albumin (BSA) and insulin (Ins) into ZIF-8 were from $75 \%$ to $100 \%$ [53].

The two ternary phase diagrams for the synthesis of ZIF- 8 biocomposite showed that the synthesis conditions could produce five different phases, including a new phase such as ZIF-CO $3-1$ [53]. The analysis of the formed phase for $\mathrm{Zn}(\mathrm{mim})_{2}$ biocomposites can be performed via a database of a web application (https://rapps.tugraz.at/apps/porousbiotech/ZIFphaseanalysis/), named ZIF phase analysis. This web application offers rapid identification of the crystalline phases and an estimation of the relative amounts (wt.\%) of each phase.

The position of protein within ZIF-8 was tracked using fluorophore-tagged proteins and confocal laser scanning microscopy (CLSM) [54]. Cryo-transmission electron microscopy was used for the direct observation of amorphous precursor phases during the synthesis of proteinZIF-8 (Figure 2) [55]. Cryo-TEM images suggested non-classical pathways via dissolutionrecrystallization of highly hydrated amorphous particles and solid-state transformation of a protein-rich amorphous phase (Figure 2) [55]. The formed amorphous phases interacted via electrostatics and eventually converted to ZIF-8 crystals. Authors observed that most p-MOF could be synthesized at various ligand: metal conditions with low isoelectric point (PI < 7) proteins. They also noticed that these protein species are biomimetic via transient phases (Figure 2).

\subsection{Enzyme@ZIF-8.}

The immobilization of enzymes onto MOFs can be achieved either using de novo methods or a post-synthetic method. De novo method is based on the immobilization of enzymes onto a pre-existing MOF. On the other side, the post-synthetic method is based on the sorption of the enzyme into the pores of MOFs. Both methods can immobilize enzymes; 
however, the final product may be different. The presence of the enzyme during the synthesis of ZIF-8 leads to perfect immobilization of the target enzyme with high confinement compared to the post-synthetic method. However, the percentage of the encapsulated enzyme is usually low.

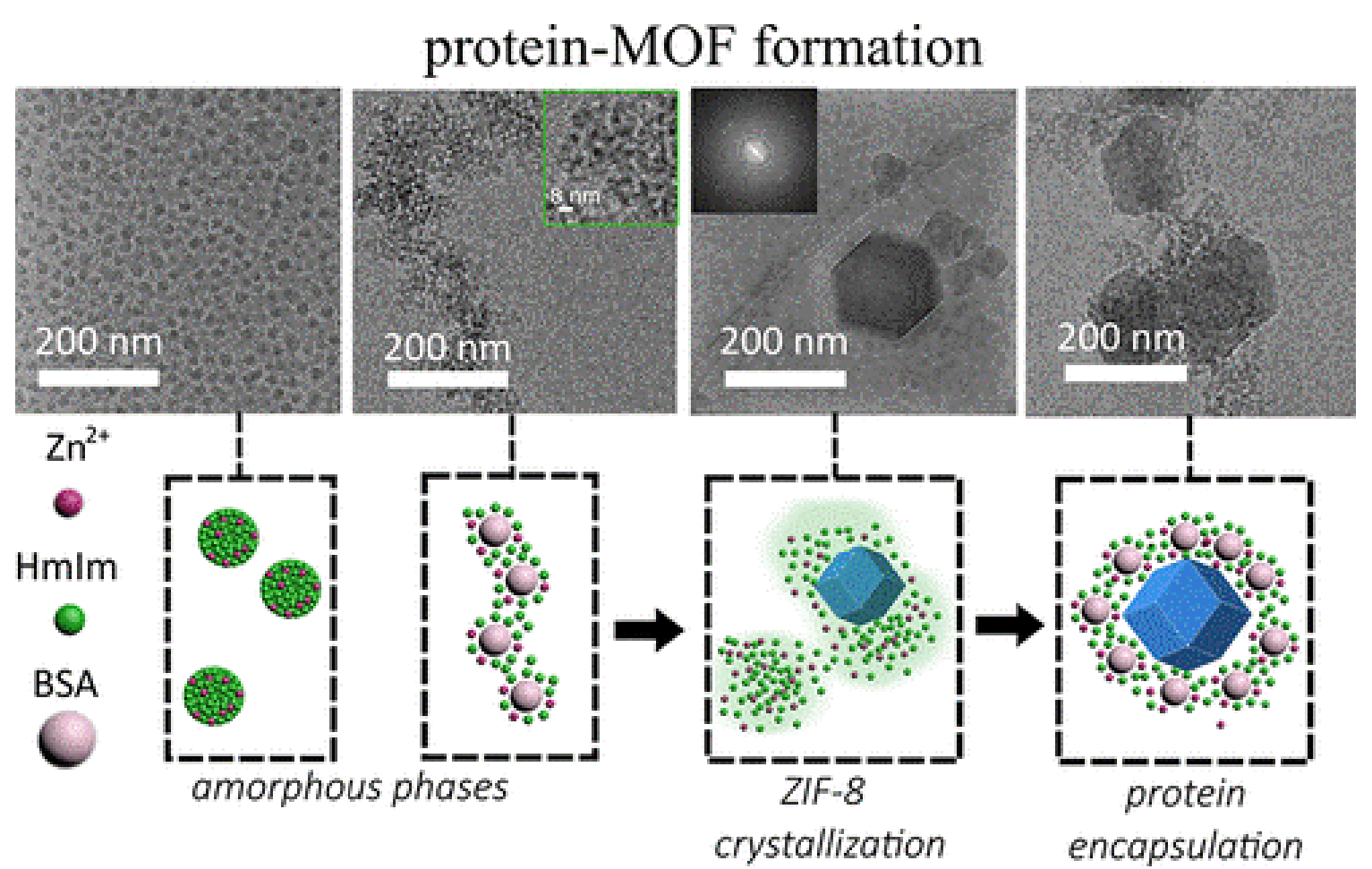

Figure 2. Mechanism of ZIF-8 formation using BSA as a modulator via cryo-TEM images [55]. Reprinted with permission from Direct Observation of Amorphous Precursor Phases in the Nucleation of Protein-Metal-

Organic Frameworks. Copyright (2020) American Chemical Society.

A hormone, insulin, was encapsulated into ZIF-8 particles [56]. At optimal concentration (below $30 \mu \mathrm{g} \bullet \mathrm{mL}^{-1}$ ), insulin@ZIF-8 can be a suitable therapeutic agent for the treatment of Diabetes I and II [56].

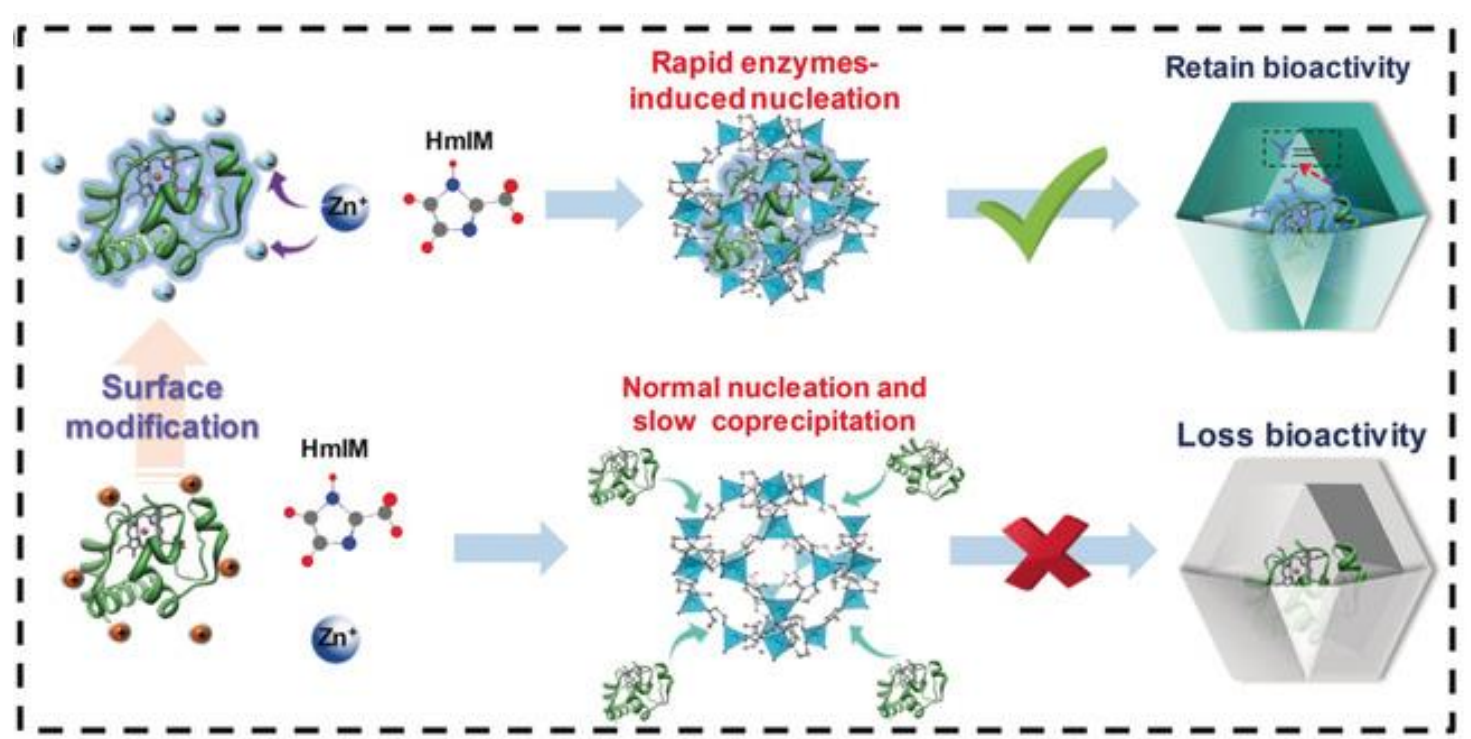

Figure 3. Schematic representation of enzymes-surface modifications using rapid enzymes and normal nucleation methods [57]. Reprinted with permission from Modulating the Biofunctionality of Metal-OrganicFramework-Encapsulated Enzymes through Controllable Embedding Patterns. Copyright (2020) John Wiley and Sons. 
The synthesis procedure of enzyme embedded ZIF-8 affects the bioactivity of the encapsulated enzyme. The synthesis procedure for six enzymes; GOx, Cyt C, HRP, CAT, urate oxidase (UOx), and alcohol dehydrogenase (ADH) into ZIF-8 was investigated (Figure 3) [57].

The synthesis procedure involved rapid enzyme-triggered nucleation of ZIF-8 to ensure bioactive materials compared to slow co-precipitation procedure which produced inactive materials (Figure 3) [57].

\subsection{Virus@ZIF-8.}

The encapsulation of the tobacco mosaic virus (TMV) into a ZIF-8 crystal (TMV@ZIF) was reported (Figure 4) [27]. The affinity of zinc ions toward the proteinaceous surface enhanced the encapsulation process and promoted the mineralization procedure. TMV@ZIF can be synthesized with different morphology such as bulky rhombic dodecahedra (containing hundreds of viruses) to discrete rod-shaped core-shell nanocomposite with a shell thickness tunable from 10-40 $\mathrm{nm}$ (Figure 4) [27].

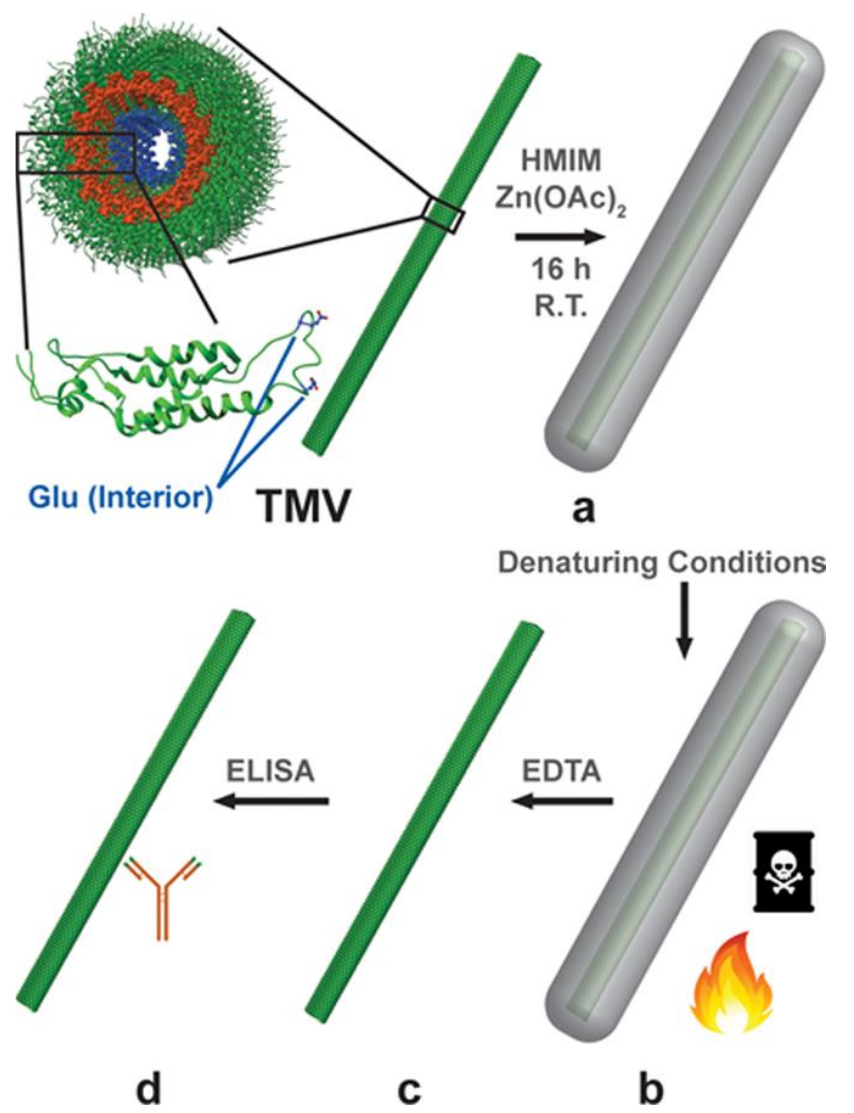

Figure 4. The synthesis procedure of TMV@ZIF; (a) Native TMV is Incubated with $\mathrm{Hmim}$ and $\mathrm{Zn}\left(\mathrm{CH}_{3} \mathrm{COO}\right)_{2}$;

(b) TMV@ZIF is subjected to denaturing conditions; (c) stressed TMV@ZIF is exfoliated with EDTA; (d)

Characterization using enzyme-linked immunosorbent assay (ELISA)[49]. Reprinted with permission from Enhanced Stability and Controlled Delivery of MOF- Encapsulated Vaccines and Their Immunogenic Response In Vivo. Copyright (2019) American Chemical Society.

These morphologies offered different colloidal and dispersion characteristics. Thus, it can be dispersible in the solution for easy injection. The presence of a core-shell morphology improved the kinetics of dissolution [49]. The encapsulation process of TMV into ZIF-8 crystals was achieved by mixing TMV with an aqueous solution of Hmim, followed by the addition of an aqueous solution of zinc acetate (Figure 4) [49]. The TMV@ZIF particles were collected after $16 \mathrm{~h}$ via centrifugation [49]. The resultant materials have high chemical and 
physical stability, ensuring the high potential for biomedical applications.TMV@ZIF particles persist in denaturing conditions, including heat and organic solvents.

The encapsulation of viruses such as TMV improved their stability against protein denaturant agents such as methanol, ethyl acetate, and guanidinium chloride [49]. Importantly, there is no change in the secondary or tertiary structure of the encapsulated protein or their ensembles.

Post-synthetic modification of ZIF-8 using oligonucleotides (ONs) and cell-penetrating peptides (CPPs) was also reported [40]. ONs-mediated assembly ZIF-8, and nanoparticles such as graphene oxide (GO), and magnetic nanoparticles (MNPs) was achieved via mixing procedure (Figure 5). Using this method, five types of non-viral vectors (ZIF-8, RhB@ZIF8, BSA@ZIF-8, MNPs@ZIF-8, and GO@ZIF-8) for three gene therapeutic agents (plasmid, splice correction oligonucleotides (SCO), and small interfering RNA (siRNA)) were synthesized. The materials exhibit low cytotoxicity with high efficiency for luciferase transfection. The presence of ZIF-8 improved the transfection of CPPs by $2-8$ folds for plasmid, SCO, and siRNA. The cell internalization takes place via scavenger class A (SCARA, Figure 5).
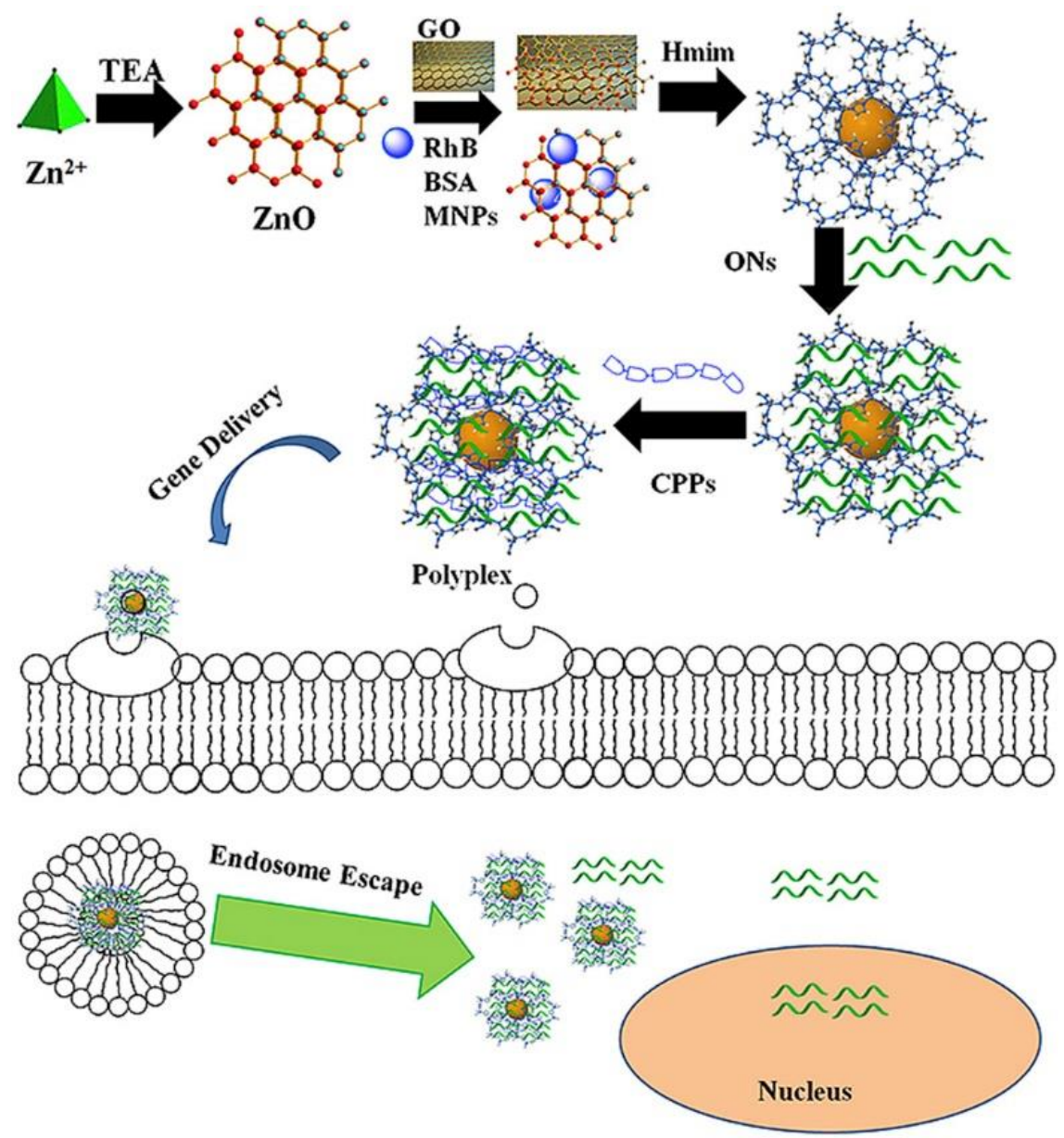

Figure 5. The synthesis of ZIF-8 polyplexes with ONs and CPPs. The figure also shows the application of the synthesized materials for gene delivery [40]. Reprinted with permission from Gene delivery using cell penetrating peptides-zeolitic imidazolate frameworks. Copyright (2020) Elsevier.

The presence of heavy metals such as zinc causes toxicity due to the generation of reactive oxygen species (ROS) [56]. Thus, ZIF-8 was used as a precursor for the synthesis of mesoporous carbon (MPC), which can be used for gene delivery (Figure 6) [39]. Biomolecules chitosan (CTS) [58-66] were used for mineralization of ZIF-8 [39]. The synthesis procedure 
occurred at room temperature in the presence of a CTS aqueous solution. These conditions offered the synthesis of a hierarchical porous ZIF-8 with micro and mesopore structure. The material was carbonized in the air at $800{ }^{\circ} \mathrm{C}$ for five $\mathrm{h}$. The metal was removed using $\mathrm{HCl}$ producing hierarchical porous carbon (MPC). There is no cytotoxicity of MPC. Thus, MPC was used as a non-viral vector for gene delivery of Luciferase-expressing plasmid (pGL3), and SCO. Two CPPs were conjugated with MPC (Figure 6). MPC enhanced the efficiency of CPPs by 10-fold (Figure 6). The improvement of CPPs is due to the presence of MCP and CPPs, which offered a synergistic effect (Figure 6).

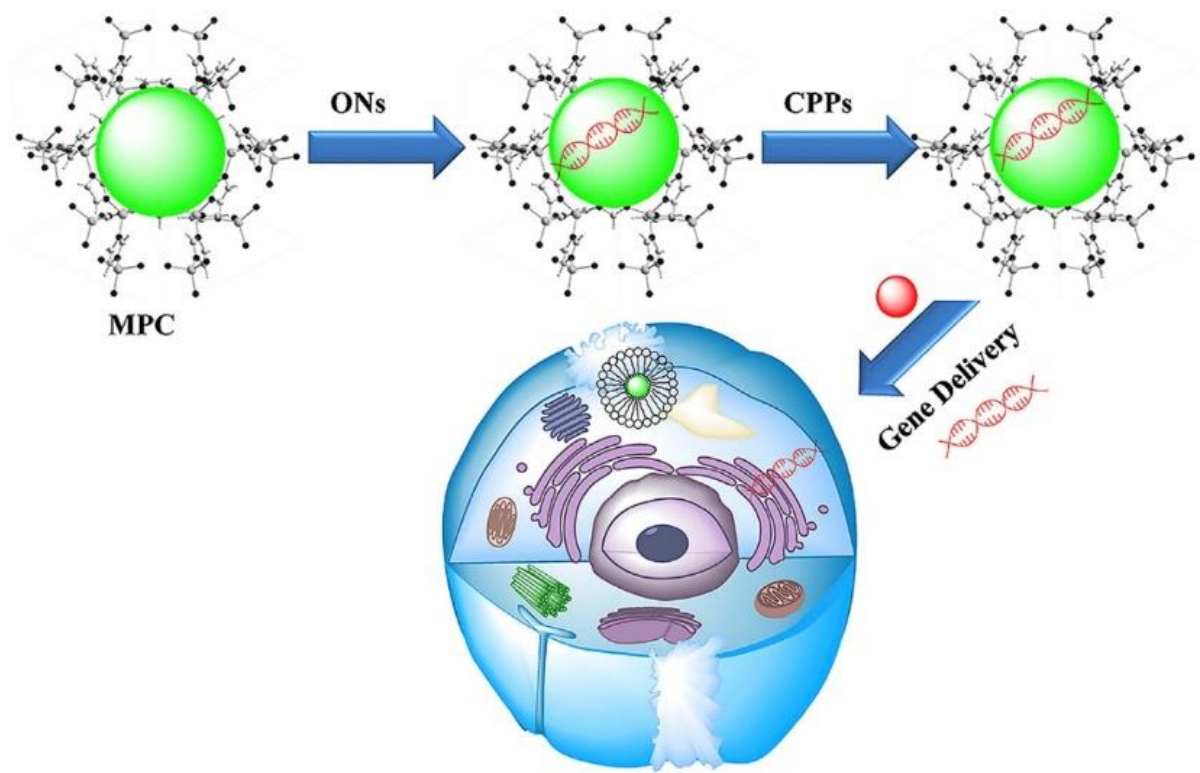

Figure 6. Schematic representation for the use of MPC for gene delivery using oligonucleotides [39]. Reprinted with permission from Carbonized chitosan encapsulated hierarchical porous zeolitic imidazolate frameworks nanoparticles for gene delivery. Copyright (2020) Elsevier.

\section{Applications of biomolecules encapsulated ZIF-8}

Biomolecules encapsulated ZIF-8 was applied for several applications such as drug delivery, biosensing, antimicrobial agents, and biocatalysis. The large surface area, as well as the simple synthesis procedure of mineralization, ensure high efficiency. ZIF-8 is biocompatible for many cells. Thus, it is widely used as a carrier and non-viral vector for gene delivery. A few examples of each application will be discussed.

ZIF-8 has used as carriers for the delivery of cytolytic peptide melittin (MLT). MLT@ZIF-8 showed high biocompatibility with excellent antitumor activity compared to free MLT [67]. The mechanism of delivery indicates the expression of 3383 genes, and the PI3K/Akt-regulated p53 pathway. MLT@ZIF-8 causes apoptosis of A549 cells (Figure 7) [67]. It showed a quantitative tumor inhibitory rate of $71 \%$ compared to the free MLT treated group, which showed an only inhibitory rate of $49 \%$ [67].

Drug delivery of insulin using ZIF-8 was reported [68,69]. GOx and insulin (Ins) were loaded into ZIF-8 to synthesis Ins \& GOx@ZIF-8 with a sphere-like morphology. Ins \& GOx@ZIF-8 particle was tested for subcutaneous insulin injection [68]. Ins \& GOx@ZIF-8 stabilizes the blood glucose level of normoglycemic state for up to $72 \mathrm{~h}$ in type 1 diabetes (T1D) [68]. Insulin and glucose oxidase-loaded cobalt-doped ZIF-8 (Ins/GOx@Co-ZIF-8) was reported for glucose-mediated transdermal medication [69]. Ins/GOx@Co-ZIF-8 offered painless administration [69]. Cobalt in the framework catalyzed the formation of $\mathrm{H}_{2} \mathrm{O}_{2}$, which 
induced decomposition and consequently released the drugs. Ins/GOx@Co-ZIF-8 offered mimic multi-enzyme systems ensuring several applications [69].

a)

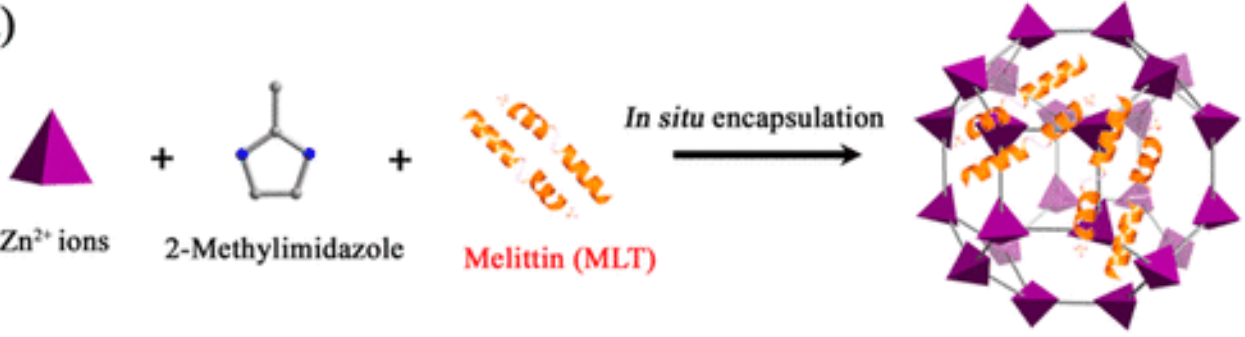

MLT@ZIF-8

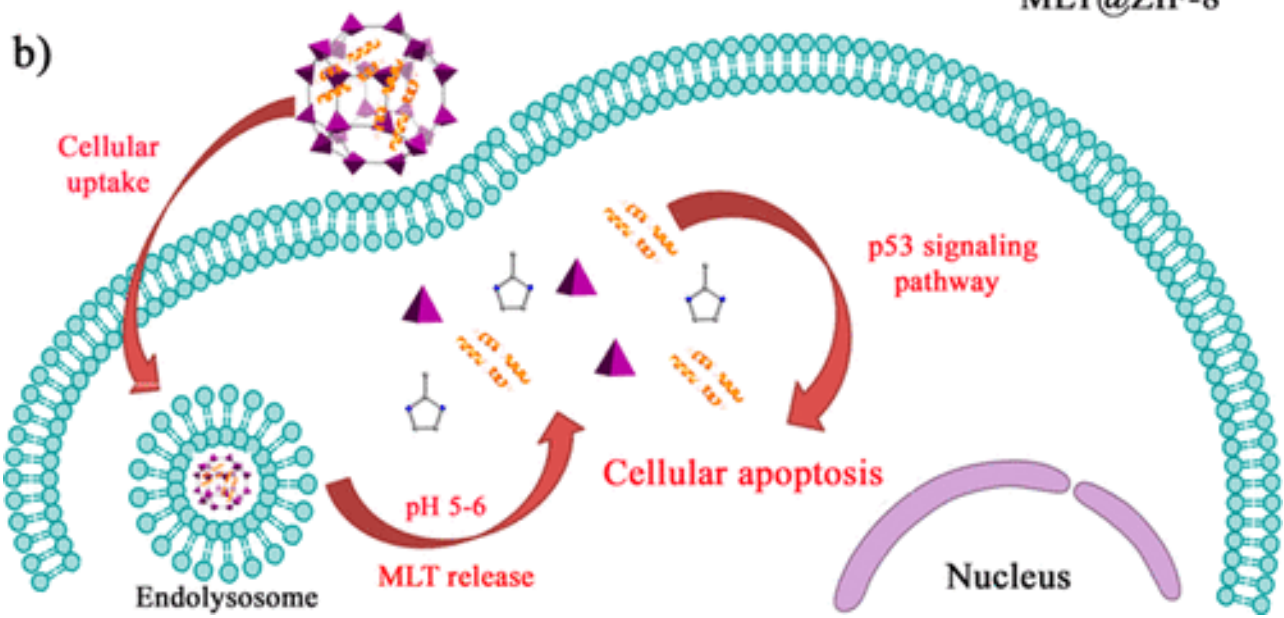

Figure 7. a) Encapsulation of MLT into ZIF-8 and their b) drug delivery [67]. Reprinted with permission from Nanoscale Melittin@Zeolitic Imidazolate Frameworks for Enhanced Anticancer Activity and Mechanism Analysis. Copyright (2018) American Chemical Society.

ZIF-8 is widely used for antibacterial agents [70]. Curcumin (CCM) loaded ZIF-8 (CCM@ZIF-8) was modified with hyaluronic acid and chitosan using the layer-by-layer method to synthesis CCM@ZIF-8@HA@CST nanoparticle [71]. CCM@ZIF8@HA@CS nanoparticle exhibited high antibacterial activity against Escherichia coli and Staphylococcus aureus [71]. The presence of photosensitizers, such as CCM offered photodynamic therapy treatment. Levofloxacin (Levo) encapsulated ZIF-8 (Levo@ZIF-8) was loaded onto the collagen-modified $\mathrm{Ti}$ substrates exhibited strong antibacterial ability against Escherichia coli and Staphylococcus aureus [72]. Levo@ZIF-8-collagen-modified Ti substrates exhibited strong antibacterial ability against Escherichia coli and Staphylococcus aureus [72]. The antibacterial activity is due to the releasing of $\mathrm{Zn}^{2+}$ as well as Levo. T4 lysozyme (T4L), which catalyzes the hydrolysis of $\beta-1,4$ glycosidic bonds of bacterial cell walls, was encapsulated into GO/ZIF-8 and GO/CaBDC [73]. Lys@GO/CaBDC was stable under acidic pH compared to lys@GO/CaBDC [73]. However, both materials exhibited antibacterial activity.

Applications of ZIF-8 for sensing and biosensing were reported. The biocatalytic efficiency of ficin (a cysteine proteolytic enzyme with peroxidase (POx) activity) can be enhanced after loading into ZIF-8 by a 2.5-fold compared to free ficin [74]. Ficin@ZIF-8 served as an enzymatic activity for a colorimetric assay for the sensing of glucose using 3,3 ,5,5 'tetramethylbenzidine dihydrochloride (TMB)- $\mathrm{H}_{2} \mathrm{O}_{2}$ system [74]. Glucose oxidase and PVI-hemin encapsulated ZIF-8 was also used for the detection of glucose and cholesterol using a colorimetric based assay [75]. Co-precipitation of glucose oxidase (GOx) into ZIF-8 offered GOx@ZIF-8 (NiPd) with high electrocatalytic activity for the oxygen reduction 
reaction (ORR) and electrochemical detection of glucose [76]. ZIFs can be used to coimmobilize two electroactive enzymes such as methylene green (MG) and glucose dehydrogenase (GDH) for in-vivo monitoring of glucose [77]. The encapsulation of horseradish peroxidase (HRP) and GOx into ZIF-8@MPs (ZIF-8@MPGOx-HRP) offered high selectivity toward glucose detection [50]. ZIF-8@MPGOx-HRP offered high selectivity toward glucose compared to other analytes including fructose, galactose, maltose, sucrose, bovine serum albumin (BSA) [50]. It retained high activity (84\%) even after 10 cycles [50]. 2D mesoporous spindle-shaped MOFs (2D MSMOFs), "cell mimic (CM)", using GOx was used for the detection of glucose [51]. MSMOFs CM offered dual signal transduction; chrominance "turnon", and fluorescence "turn-off".

ZIF-8 coated $\mathrm{Fe}_{3} \mathrm{O}_{4}$ magnetic nanoparticle clusters (MNCs) were synthesized and used to detect pathogenic bacteria $S$. aureus in milk [78]. The bacteria cells were captured and separated using an external magnet. The cells after separation were determined using portable adenosine triphosphate (ATP) luminometer offering a detection limit of $300 \mathrm{cfu} \cdot \mathrm{mL}^{-1}$ [78]. The GOx-ZIF-8 composite was used as a signal transduction unit for sensing galectin- 4 using fluorescence immunosensor [79]. This method is based on the measurements of hydroxyl radical $\left({ }^{\circ} \mathrm{OH}\right)$ that can be generated from the reaction between hydrogen peroxide $\left(\mathrm{H}_{2} \mathrm{O}_{2}\right)$ and iron (II) ions. The hydroxy radical $\left({ }^{\circ} \mathrm{OH}\right)$ causes quenching of the fluorescence of gold nanoclusters (Au NCs).

Cytochrome (Cyt c) embedded ZIF-8 composites (Cyt c/ZIF-8, 10 wt.\% of Cyt c) was prepared using a co-precipitation method [80]. Cyt c/ZIF-8 was used for fluorometric sensing of $\mathrm{H}_{2} \mathrm{O}_{2}$ and explosive peroxides (i.e., methyl ethyl ketone peroxide (MEKP) and tertiary butyl hydroperoxide (TBHP)) using $N$-acetyl-3,7-dihydroxyphenoxazine (Amplex Red) as a substrate [80]. Cyt c/ZIF-8 catalyzed the oxidation of Amplex Red to produce fluorescently active resorufin. The emission of resorufin was used to detect the peroxide species. Bovine hemoglobin (BHb) ZIF-8 composites (BHb@ZIF-8) was synthesized using the de novo procedure [81]. BHb@ZIF-8 was used as a colorimetric sensor for $\mathrm{H}_{2} \mathrm{O}_{2}$ and phenol [81].

Urease@ZIF-8 was synthesized via an in situ growth approach on the coreless fibers [82]. This approach offered single-mode coreless single-mode (SCS) optical fiber for the analysis of urea. SCS exhibit several advantages, such as fast response, high sensitivity, and optical-based label-free detection. A trypsin-immobilized magnetic ZIF-8 (iron oxide@ ZIF$8 @$ trypsin) was used for the proteolysis of protein for the analysis using matrix-assisted laser desorption/ionization mass spectrometry [83]. Electrochemical-based biosensing using biomolecules embedded ZIF was reported. Streptavidin (SA)-labeled graphene quantum dots (GQDs)-embedded ZIF-8 polyhedra was used as a signal quencher of photoelectrochemical (PEC) biosensor for M.SssI MTase activity assay [84]. An electrochemical biosensor was reported using graphene@ZIF-8 hybrids anchored gold nanoclusters (AuNCs-GR@ZIF-8), and hemin/G-quadruplex DNAzyme decorated layered-branched hybridization chain reaction (LB-HCR) for the detection of interferon-gamma (IFN- $\gamma$ ) [85].

ZIF-8 was reported as support for an enzyme for biocatalysis. Combi-MOF using ZIF8 and $\alpha$-amylase and glucoamylase was investigated for the one-pot hydrolysis of starch [86]. Combi-MOF showed extraordinary storage stability until 24 days with high recyclability in batch mode, which retained up to $52 \%$ residual activity after five cycles [86]. Collagenase from Clostridium histolyticum-embedded ZIF-8 was reported for the proteolysis of a collagenlike peptide [87]. The activity of collagenase@ZIF-8 and pure collagenase were $0.009 \pm 0.001$ $\mathrm{U} \cdot \mathrm{mL}^{-1}$, and $0.111 \pm 0.004 \mathrm{U} \cdot \mathrm{mL}^{-1}$, respectively. The lower activity of collagenase@ZIF-8 is 
due to the physical impediment of the enzyme caused by ZIF-8. ZIF-8 created a barrier that prevents contact between the enzyme and the substrate apart. Several advantages can be achieved via encapsulation. The efficiency of Cyt $\mathrm{c}$ after encapsulation into ZIF-8 exhibited a increase (10-fold) in the peroxidase activity of Cyt c [80]. Two enzymes; such as glucose oxidase and PVI-hemin can be encapsulated into ZIF-8 [75]. However, the nature of ZIF-8 may affect the catalytic performance of the encapsulated enzyme. The hydrophobic nature of ZIF8 deactivated the enzymatic activity of catalase [88].

ZIF-8 can be used to encapsulate enzyme and nanoparticle. Horseradish peroxidase (HRP), and iron oxide magnetic nanoparticles were encapsulated into ZIF-8 to form HRP/MNP@ZIF-8 [89]. This combination offered high catalytic activity and a simple separation method using an external magnet. MNPs increased the encapsulation efficiency (EE\%) of HRP from $\sim 82 \%$ in the absence of MNPs to $\sim 86 \%$ and $\sim 94 \%$ via the addition of $0.33 \mathrm{mg} \bullet \mathrm{mL}^{-1}$ and $1.00 \mathrm{mg} \bullet \mathrm{mL}^{-1}$ of MNPs, respectively. The presence of MNPs enhanced the specific activity from $1.1 \mathrm{U} \cdot \mathrm{mg}^{-1}$ to $3.0 \mathrm{U} \cdot \mathrm{mg}^{-1}$ ( 270\% increase) [89]. De novo synthesis of Cyt c@ZIF-8/GO was reported [90]. Cyt c@ZIF-8/GO exhibited an activity of approximately $100 \%$ even after storage in ethanol and acetone for two hours. It showed higher activity compared to Cyt c, Cyt c@ZIF-8, and Cyt c@GO which displayed the activity of 10\%, 50\%, and 40\%, respectively [90]. Cyt c@ZIF-8/GO showed low protein leakage compared to Cyt c@ZIF-8, and Cyt c@GO which displayed 30\% and 60\% protein after 60 h of storage [90].

\section{Conclusions}

The biointerface between biomolecules and ZIF-8 offered several advantages. The presence of different functional groups in the biomolecules, such as protein, peptide, oligonucleotides, ensures strong interactions with ZIF-8 precursors. Thus, biomolecules assisted the synthesis of ZIF-8 crystals and improved the yield of the resultant materials. The one-pot synthesis procedure of ZIF-8 in the presence of the target species was simple, fast, and required no special equipment. Biomolecules and nanoparticles can be combined into ZIF-8 crystal. Two enzymes can also be conjugated in the same crystal. These combinations offered multi-enzymatic activity. The full characterization of the biomolecules-ZIF- 8 biocomposite is difficult, and further efforts are highly required to understand the material's performance. The mechanism of the material's formation is necessary and required extra investigations.

\section{Funding}

This research received no external funding.

\section{Acknowledgments}

The author would thank the Ministry of Higher Education and Scientific Research (MHESR) and Institutional Review Board (IRB) of the Faculty of Science at Assiut University, Egypt, for the support.

\section{Conflicts of Interest}

The authors declare no conflict of interest. 


\section{References}

1. Zhou, H.C.; Long, J.R.; Yaghi, O.M. Introduction to metal-organic frameworks. Chem. Rev. 2012, 112, 6734, https://doi.org/10.1021/cr300014x.

2. Furukawa, H.; Cordova, K.E.; O’Keeffe, M.; Yaghi, O.M. The Chemistry and Applications of Metal-Organic Frameworks. Science (80-. ). 2013, 341, 1230444-1230444, https://doi.org/10.1126/science.1230444.

3. Trickett, C.A.; Helal, A.; Al-Maythalony, B.A.; Yamani, Z.H.; Cordova, K.E.; Yaghi, O.M. The chemistry of metal-organic frameworks for $\mathrm{CO} 2$ capture, regeneration and conversion. Nat. Rev. Mater. 2017, 2 , https://doi.org/10.1038/natrevmats.2017.45.

4. Furukawa, H.; Ko, N.; Go, Y.B.; Aratani, N.; Choi, S.B.; Choi, E.; Yazaydin, A.Ö.; Snurr, R.Q.; O’Keeffe, M.; Kim, J.; Yaghi, O.M. Ultrahigh Porosity in Metal-Organic Frameworks. Science (80-. ) 2010, 329, 424428, https://doi.org/10.1126/science.1192160.

5. Abdelhamid, H.N. Lanthanide Metal-Organic Frameworks and Hierarchical Porous Zeolitic Imidazolate Frameworks: Synthesis, Properties, and Applications. Stockholm University, Faculty of Science,: Stockholm, 2017.

6. Abdellah, A.R.; Abdelhamid, H.N.; El-Adasy, A.B.A.A.M.; Atalla, A.A.; Aly, K.I. One-pot synthesis of hierarchical porous covalent organic frameworks and two-dimensional nanomaterials for selective removal of anionic dyes. J. Environ. Chem. Eng. 2020, 8, https://doi.org/10.1016/j.jece.2020.104054.

7. Abdelhamid, H.N. Surfactant assisted synthesis of hierarchical porous metal-organic frameworks nanosheets. Nanotechnology 2019, 30.

8. Yao, Q.; Bermejo Gómez, A.; Su, J.; Pascanu, V.; Yun, Y.; Zheng, H.; Chen, H.; Liu, L.; Abdelhamid, H.N.; Martín-Matute, B.; Zou, X. Series of Highly Stable Isoreticular Lanthanide Metal-Organic Frameworks with Expanding Pore Size and Tunable Luminescent Properties. Chem. Mater. 2015, 27, 5332-5339, https://doi.org/10.1021/acs.chemmater.5b01711.

9. Abdelhamid, H.N.; Bermejo-Gómez, A.; Martín-Matute, B.; Zou, X. A water-stable lanthanide metalorganic framework for fluorimetric detection of ferric ions and tryptophan. Microchim. Acta 2017, 184, 3363-3371, https://doi.org/10.1007/s00604-017-2306-0.

10. Yang, Y.; Shen, K.; Lin, J.; Zhou, Y.; Liu, Q.; Hang, C.; Abdelhamid, H.N.; Zhang, Z.; Chen, H. A Zn-MOF constructed from electron-rich $\pi$-conjugated ligands with an interpenetrated graphene-like net as an efficient nitroaromatic sensor. RSC Adv. 2016, 6, 45475-45481, https://doi.org/10.1039/C6RA00524A.

11. Abdelhamid, H.N.; Wilk-Kozubek, M.; El-Zohry, A.M.; Bermejo Gómez, A.; Valiente, A.; Martín-Matute, B.; Mudring, A.V.; Zou, X. Luminescence properties of a family of lanthanide metal-organic frameworks. Microporous Mesoporous Mater. 2019, 279, 400-406, https://doi.org/10.1016/j.micromeso.2019.01.024.

12. Emam, H.E.; Abdelhamid, H.N.; Abdelhameed, R.M. Self-cleaned photoluminescent viscose fabric incorporated lanthanide-organic framework (Ln-MOF). Dye. Pigment. 2018, 159, 491-498, https://doi.org/10.1016/j.dyepig.2018.07.026.

13. Abdelhamid, H.N. Organic matrices, ionic liquids, and organic matrices@nanoparticles assisted laser desorption/ionization mass spectrometry. TrAC Trends Anal. Chem. 2017, 89, 68-98, https://doi.org/10.1016/j.trac.2017.01.012.

14. Abdelhamid, H.N.; Wu, H.F. Proteomics analysis of the mode of antibacterial action of nanoparticles and their interactions with proteins. TrAC Trends Anal. Chem. 2015, 65, 30-46, https://doi.org/10.1016/j.trac.2014.09.010.

15. Abdelhamid, H.N. Nanoparticles Assisted Laser Desorption/Ionization Mass Spectrometry. In: Handbook of Smart Materials in Analytical Chemistry. John Wiley \& Sons, Ltd: Chichester, UK, 2019; pp. 729-755.

16. Abdelhamid, H.N.; Wu, H.F. A New Binary Matrix for Specific Detection of Mercury(II) Using MatrixAssisted Laser Desorption Ionization Mass Spectrometry. J. Am. Soc. Mass Spectrom. 2019, 30, 2617-2622, https://doi.org/10.1007/s13361-019-02324-1.

17. Abdelhamid, H.N. Nanoparticle assisted laser desorption/ionization mass spectrometry for small molecule analytes. Microchim. Acta 2018, 185, https://doi.org/10.1007/s00604-018-2687-8.

18. Abdelhamid, H.N. Nanoparticle-based surface assisted laser desorption ionization mass spectrometry: a review. Microchim. Acta 2019, 186, https://doi.org/10.1007/s00604-019-3770-5.

19. Kassem, A.A.; Abdelhamid, H.N.; Fouad, D.M.; Ibrahim, S.A. Metal-organic frameworks (MOFs) and MOFs-derived $\mathrm{CuO} @ \mathrm{C}$ for hydrogen generation from sodium borohydride. Int. J. Hydrogen Energy 2019, 44, 31230-31238, https://doi.org/10.1016/j.ijhydene.2019.10.047.

20. Goda, M.N.; Abdelhamid, H.N.; Said, A.E.A.A. Zirconium Oxide Sulfate-Carbon (ZrOSO4@C) Derived from Carbonized UiO-66 for Selective Production of Dimethyl Ether. ACS Appl. Mater. Interfaces 2020, 12 , 646-653, https://doi.org/10.1021/acsami.9b17520.

21. Kassem, A.A.; Abdelhamid, H.N.; Fouad, D.M.; Ibrahim, S.A. Hydrogenation reduction of dyes using metalorganic framework-derived CuO@C. Microporous Mesoporous Mater. 2020, 305, https://doi.org/10.1016/j.micromeso.2020.110340.

22. Zhang, X.; Li, G.; Wu, D.; Li, X.; Hu, N.; Chen, J.; Chen, G.; Wu, Y. Recent progress in the design fabrication of metal-organic frameworks-based nanozymes and their applications to sensing and cancer therapy. Biosens. Bioelectron. 2019, 137, 178-198, https://doi.org/10.1016/j.bios.2019.04.061. 
23. Imaz, I.; Rubio-Martínez, M.; An, J.; Solé-Font, I.; Rosi, N.L.; Maspoch, D. Metal-biomolecule frameworks (MBioFs). Chem. Commun. 2011, 47, 7287, https://doi.org/10.1039/c1cc11202c.

24. Doonan, C.; Riccò, R.; Liang, K.; Bradshaw, D.; Falcaro, P. Metal-Organic Frameworks at the Biointerface: Synthetic Strategies and Applications. Acc. Chem. Res. 2017, 50, 1423-1432, https://doi.org/10.1021/acs.accounts.7b00090.

25. Kempahanumakkagari, S.; Kumar, V.; Samaddar, P.; Kumar, P.; Ramakrishnappa, T.; Kim, K.H. Biomolecule-embedded metal-organic frameworks as an innovative sensing platform. Biotechnol. Adv. 2018, 36, 467-481, https://doi.org/10.1016/j.biotechadv.2018.01.014.

26. Riccò, R.; Liang, W.; Li, S.; Gassensmith, J.J.; Caruso, F.; Doonan, C.; Falcaro, P. Metal-Organic Frameworks for Cell and Virus Biology: A Perspective. ACS Nano 2018, 12, 13-23, https://doi.org/10.1021/acsnano.7b08056.

27. Li, S.; Dharmarwardana, M.; Welch, R.P.; Benjamin, C.E.; Shamir, A.M.; Nielsen, S.O.; Gassensmith, J.J. Investigation of Controlled Growth of Metal-Organic Frameworks on Anisotropic Virus Particles. ACS Appl. Mater. Interfaces 2018, 10, 18161-18169, https://doi.org/10.1021/acsami.8b01369.

28. Li, X.; Li, D.; Zhang, Y.; Lv, P.; Feng, Q.; Wei, Q. Encapsulation of enzyme by metal-organic framework for single-enzymatic biofuel cell-based self-powered biosensor. Nano Energy 2020, 68, 104308, https://doi.org/10.1016/j.nanoen.2019.104308.

29. Park, K.S.; Ni, Z.; Cote, A.P.; Choi, J.Y.; Huang, R.; Uribe-Romo, F.J.; Chae, H.K.; O’Keeffe, M.; Yaghi, O.M. Exceptional chemical and thermal stability of zeolitic imidazolate frameworks. Proc. Natl. Acad. Sci. 2006, 103, 10186-10191, https://doi.org/10.1073/pnas.0602439103.

30. Abdelhamid, H.N.; Huang, Z.; El-Zohry, A.M.; Zheng, H.; Zou, X. A Fast and Scalable Approach for Synthesis of Hierarchical Porous Zeolitic Imidazolate Frameworks and One-Pot Encapsulation of Target Molecules. Inorg. Chem. 2017, 56, 9139-9146, https://doi.org/10.1021/acs.inorgchem.7b01191.

31. Sultan, S.; Abdelhamid, H.N.; Zou, X.; Mathew, A.P. CelloMOF: Nanocellulose Enabled 3D Printing of Metal-Organic Frameworks. Adv. Funct. Mater. 2018, https://doi.org/10.1002/adfm.201805372.

32. Abdelhamid, H.N.; Zou, X. Template-free and room temperature synthesis of hierarchical porous zeolitic imidazolate framework nanoparticles and their dye and CO 2 sorption. Green Chem. 2018, 20, 1074-1084, https://doi.org/10.1039/C7GC03805D.

33. Valencia, L.; Abdelhamid, H.N. Nanocellulose leaf-like zeolitic imidazolate framework (ZIF-L) foams for selective capture of carbon dioxide. Carbohydr. Polym. 2019, 213, 338-345, https://doi.org/10.1016/j.carbpol.2019.03.011.

34. Abdel-Magied, A.F.; Abdelhamid, H.N.; Ashour, R.M.; Zou, X.; Forsberg, K. Hierarchical porous zeolitic imidazolate frameworks nanoparticles for efficient adsorption of rare-earth elements. Microporous Mesoporous Mater. 2019, 278, 175-184, https://doi.org/10.1016/j.micromeso.2018.11.022.

35. Feng, S.; Zhang, X.; Shi, D.; Wang, Z. Zeolitic imidazolate framework-8 (ZIF-8) for drug delivery: A critical review. Front. Chem. Sci. Eng. 2020, https://doi.org/10.1007/s11705-020-1927-8.

36. Keservani, R.; Sharma, A.; Abdelhamid, H. Nanoparticulate Drug Delivery Systems. Keservani, R.K.; Sharma, A.K. Eds.; CRC Press, 2019.

37. Abdelhamid, H.N.; Wu, H.F. Nanoparticles Advance Drug Delivery for Cancer Cells. In: Nanoparticulate Drug Delivery Systems. Keservani, R.K.; Sharma, A.K. Eds.; Apple Academic Press: USA, 2019; pp. 121150 .

38. Abdelhamid, H.N.; Dowaidar, M.; Hällbrink, M.; Langel, Ü. Cell Penetrating Peptides-Hierarchical Porous Zeolitic Imidazolate Frameworks Nanoparticles: An Efficient Gene Delivery Platform. SSRN Electron. J. 2019, https://doi.org/10.2139/ssrn.3435895.

39. Abdelhamid, H.N.; Dowaidar, M.; Langel, Ü. Carbonized chitosan encapsulated hierarchical porous zeolitic imidazolate frameworks nanoparticles for gene delivery. Microporous Mesoporous Mater. 2020, https://doi.org/10.1016/j.micromeso.2020.110200.

40. Abdelhamid, H.N.; Dowaidar, M.; Hällbrink, M.; Langel, Ü. Gene delivery using cell penetrating peptideszeolitic imidazolate frameworks. Microporous Mesoporous Mater. 2020, 300, https://doi.org/10.1016/j.micromeso.2020.110173.

41. Abdelhamid, H.N. Salts Induced Formation of Hierarchical Porous ZIF-8 and Their Applications for CO 2 Sorption and Hydrogen Generation via NaBH 4 Hydrolysis. Macromol. Chem. Phys. 2020, 221, https://doi.org/10.1002/macp.202000031.

42. Abdelhamid, H.N. Hierarchical porous ZIF-8 for hydrogen production via the hydrolysis of sodium borohydride. Dalt. Trans. 2020, 49, 4416-4424, https://doi.org/10.1039/D0DT00145G.

43. Abdelhamid, H.N.; El-Zohry, A.M.; Cong, J.; Thersleff, T.; Karlsson, M.; Kloo, L.; Zou, X. Towards implementing hierarchical porous zeolitic imidazolate frameworks in dye-sensitized solar cells. R. Soc. Open Sci. 2019, 6, https://doi.org/10.1098/rsos.190723.

44. Abdelhamid, H.N. Zinc hydroxide nitrate nanosheets conversion into hierarchical zeolitic imidazolate frameworks nanocomposite and their application for $\mathrm{CO} 2$ sorption. Mater. Today Chem. 2020, 15, https://doi.org/10.1016/j.mtchem.2019.100222.

45. Abdelhamid, H.N. Dye encapsulated hierarchical porous zeolitic imidazolate frameworks for carbon dioxide adsorption. J. Environ. Chem. Eng. 2020, 8, https://doi.org/10.1016/j.jece.2020.104008. 
46. Zhang, J.; Tan, Y.; Song, W.J. Zeolitic imidazolate frameworks for use in electrochemical and optical chemical sensing and biosensing: a review. Microchim. Acta 2020, 187, 234, https://doi.org/10.1007/s00604020-4173-3.

47. Sun, C.Y.; Qin, C.; Wang, X.L.; Yang, G.S.; Shao, K.Z.; Lan, Y.Q.; Su, Z.M.; Huang, P.; Wang, C.G.; Wang, E.B. Zeolitic Imidazolate framework-8 as efficient $\mathrm{pH}$-sensitive drug delivery vehicle. Dalton Trans. 2012, 41, 6906-9, https://doi.org/10.1039/c2dt30357d.

48. Asadniaye Fardjahromi, M.; Razmjou, A.; Vesey, G.; Ejeian, F.; Banerjee, B.; Chandra Mukhopadhyay, S.; Ebrahimi Warkiani, M. Mussel inspired ZIF8 microcarriers: a new approach for large-scale production of stem cells. RSC Adv. 2020, 10, 20118-20128, https://doi.org/10.1039/D0RA04090H.

49. Luzuriaga, M.A.; Welch, R.P.; Dharmarwardana, M.; Benjamin, C.E.; Li, S.; Shahrivarkevishahi, A.; Popal, S.; Tuong, L.H.; Creswell, C.T.; Gassensmith, J.J. Enhanced Stability and Controlled Delivery of MOFEncapsulated Vaccines and Their Immunogenic Response In Vivo. ACS Appl. Mater. Interfaces 2019, 11, 9740-9746, https://doi.org/10.1021/acsami.8b20504.

50. Zhou, Z.; Gao, Z.; Shen, H.; Li, M.; He, W.; Su, P.; Song, J.; Yang, Y. Metal-Organic Framework in Situ Post-Encapsulating DNA-Enzyme Composites on a Magnetic Carrier with High Stability and Reusability. ACS Appl. Mater. Interfaces 2020, 12, 7510-7517, https://doi.org/10.1021/acsami.9b23526.

51. Chen, G.; Huang, S.; Kou, X.; Zhu, F.; Ouyang, G. Embedding Functional Biomacromolecules within Peptide-Directed Metal-Organic Framework (MOF) Nanoarchitectures Enables Activity Enhancement. Angew. Chemie Int. Ed. 2020, https://doi.org/10.1002/anie.202005529.

52. Zou, D.; Yu, L.; Sun, Q.; Hui, Y.; Tengjisi; Liu, Y.; Yang, G.; Wibowo, D.; Zhao, C.X. A general approach for biomimetic mineralization of MOF particles using biomolecules. Colloids Surfaces B Biointerfaces 2020, 193, https://doi.org/10.1016/j.colsurfb.2020.111108.

53. Carraro, F.; Velásquez-Hernández, M.d.J.; Astria, E.; Liang, W.; Twight, L.; Parise, C.; Ge, M.; Huang, Z.; Ricco, R.; Zou, X.; Villanova, L.; Kappe, C.O.; Doonan, C.; Falcaro, P. Phase dependent encapsulation and release profile of ZIF-based biocomposites. Chem. Sci. 2020, 11, 3397-3404, https://doi.org/10.1039/C9SC05433B.

54. Liang, W.; Ricco, R.; Maddigan, N.K.; Dickinson, R.P.; Xu, H.; Li, Q.; Sumby, C.J.; Bell, S.G.; Falcaro, P.; Doonan, C.J. Control of Structure Topology and Spatial Distribution of Biomacromolecules in Protein@ZIF8 Biocomposites. Chem. Mater. 2018, 30, 1069-1077, https://doi.org/10.1021/acs.chemmater.7b04977.

55. Ogata, A.F.; Rakowski, A.M.; Carpenter, B.P.; Fishman, D.A.; Merham, J.G.; Hurst, P.J.; Patterson, J.P. Direct Observation of Amorphous Precursor Phases in the Nucleation of Protein-Metal-Organic Frameworks. J. Am. Chem. Soc. 2020, 142, 1433-1442, https://doi.org/10.1021/jacs.9b11371.

56. Hoop, M.; Walde, C.F.; Riccò, R.; Mushtaq, F.; Terzopoulou, A.; Chen, X.Z.; deMello, A.J.; Doonan, C.J.; Falcaro, P.; Nelson, B.J.; Puigmartí-Luis, J.; Pané, S. Biocompatibility characteristics of the metal organic framework ZIF-8 for therapeutical applications. Applied Materials Today 2018, 11, 13-21, Biocompatibility characteristics of the metal organic framework ZIF-8 for therapeutical applications. Appl. Mater. Today 2018, 11, 13-21, https://doi.org/10.1016/j.apmt.2017.12.014.

57. Chen, G.; Kou, X.; Huang, S.; Tong, L.; Shen, Y.; Zhu, W.; Zhu, F.; Ouyang, G. Modulating the Biofunctionality of Metal-Organic-Framework-Encapsulated Enzymes through Controllable Embedding Patterns. Angew. Chemie Int. Ed. 2020, 59, 2867-2874, https://doi.org/10.1002/anie.201913231.

58. Abdelhamid, H.N.; Wu, H.F. Multifunctional graphene magnetic nanosheet decorated with chitosan for highly sensitive detection of pathogenic bacteria. J. Mater. Chem. B 2013, 1, 3950-3961, https://doi.org/10.1039/c3tb20413h.

59. Abdelhamid, H.N.; Wu, H.F. Probing the interactions of chitosan capped CdS quantum dots with pathogenic bacteria and their biosensing application. J. Mater. Chem. B 2013, 1, 6094-6106, https://doi.org/10.1039/c3tb21020k.

60. Gopal, J.; Abdelhamid, H.N.; Hua, P.Y.; Wu, H.F. Chitosan nanomagnets for effective extraction and sensitive mass spectrometric detection of pathogenic bacterial endotoxin from human urine. J. Mater. Chem. B 2013, 1, 2463, https://doi.org/10.1039/c3tb20079e.

61. Abdelhamid, H.N.; Lin, Y.C.; Wu, H.F. Thymine chitosan nanomagnets for specific preconcentration of mercury(II) prior to analysis using SELDI-MS. Microchim. Acta 2017, 184, 1517-1527, https://doi.org/10.1007/s00604-017-2125-3.

62. Abdelhamid, H.N.; Lin, Y.C.; Wu, H.F. Magnetic nanoparticle modified chitosan for surface enhanced laser desorption/ionization mass spectrometry of surfactants. RSC Adv. 2017, 7, 41585-41592, https://doi.org/10.1039/C7RA05982E.

63. Dowaidar, M.; Nasser Abdelhamid, H.; Hällbrink, M.; Langel, Ü.; Zou, X. Chitosan enhances gene delivery of oligonucleotide complexes with magnetic nanoparticles-cell-penetrating peptide. J. Biomater. Appl. 2018, 33, 392-401, https://doi.org/10.1177/0885328218796623.

64. Abdelhamid, H.N.; Wu, H.F. Selective biosensing of Staphylococcus aureus using chitosan quantum dots. Spectrochim. Acta - Part A Mol. Biomol. Spectrosc. 2018, 188, 50-56, https://doi.org/10.1016/j.saa.2017.06.047.

65. Abdelhamid, H.N.; Wu, H.F. Synthesis and multifunctional applications of quantum nanobeads for labelfree and selective metal chemosensing. RSC Adv. 2015, 5, 50494-50504, 
https://doi.org/10.1039/c5ra07069d.

66. Abdelhamid, H.N.; El-Bery, H.M.; Metwally, A.A.; Elshazly, M.; Hathout, R.M. Synthesis of CdS-modified chitosan quantum dots for the drug delivery of Sesamol. Carbohydr. Polym. 2019, 214, 90-99, https://doi.org/10.1016/j.carbpol.2019.03.024.

67. Li, Y.; Xu, N.; Zhu, W.; Wang, L.; Liu, B.; Zhang, J.; Xie, Z.; Liu, W. Nanoscale Melittin@Zeolitic Imidazolate Frameworks for Enhanced Anticancer Activity and Mechanism Analysis. ACS Appl. Mater. Interfaces 2018, 10, 22974-22984, https://doi.org/10.1021/acsami.8b06125.

68. Zhang, C.; Hong, S.; Liu, M.D.; Yu, W.Y.; Zhang, M.K.; Zhang, L.; Zeng, X.; Zhang, X.Z. pH-sensitive MOF integrated with glucose oxidase for glucose-responsive insulin delivery. J. Control. Release 2020, 320, 159-167, https://doi.org/10.1016/j.jconrel.2020.01.038.

69. Yang, X.X.; Feng, P.; Cao, J.; Liu, W.; Tang, Y. Composition-Engineered Metal-Organic Framework-Based Microneedles for Glucose-Mediated Transdermal Insulin Delivery. ACS Appl. Mater. Interfaces 2020, 12, 13613-13621, https://doi.org/10.1021/acsami.9b20774.

70. Maleki, A.; Shahbazi, M.; Alinezhad, V.; Santos, H.A. The Progress and Prospect of Zeolitic Imidazolate Frameworks in Cancer Therapy, Antibacterial Activity, and Biomineralization. Adv. Healthc. Mater. 2020, https://doi.org/10.1002/adhm.202000248.

71. Duan, S.; Zhao, X.; Su, Z.; Wang, C.; Lin, Y. Layer-by-Layer Decorated Nanoscale ZIF-8 with High Curcumin Loading Effectively Inactivates Gram-Negative and Gram-Positive Bacteria. ACS Appl. Bio Mater. 2020, 3, 3673-3680, https://doi.org/10.1021/acsabm.0c00300.

72. Tao, B.; Zhao, W.; Lin, C.; Yuan, Z.; He, Y.; Lu, L.; Chen, M.; Ding, Y.; Yang, Y.; Xia, Z.; Cai, K. Surface modification of titanium implants by ZIF-8@Levo/LBL coating for inhibition of bacterial-associated infection and enhancement of in vivo osseointegration. Chem. Eng. J. 2020, 390, https://doi.org/10.1016/j.cej.2020.124621.

73. Farmakes, J.; Schuster, I.; Overby, A.; Alhalhooly, L.; Lenertz, M.; Li, Q.; Ugrinov, A.; Choi, Y.; Pan, Y.; Yang, Z. Enzyme Immobilization on Graphite Oxide (GO) Surface via One-Pot Synthesis of GO/MetalOrganic Framework Composites for Large-Substrate Biocatalysis. ACS Appl. Mater. Interfaces 2020, 12, 23119-23126, https://doi.org/10.1021/acsami.0c04101.

74. Pan, Y.; Pang, Y.; Shi, Y.; Zheng, W.; Long, Y.; Huang, Y.; Zheng, H. One-pot synthesis of a composite consisting of the enzyme ficin and a zinc(II)-2-methylimidazole metal organic framework with enhanced peroxidase activity for colorimetric detection for glucose. Microchim. Acta 2019, 186, https://doi.org/10.1007/s00604-019-3331-y.

75. Zhang, X.; Zhang, F.; Lu, Z.; Xu, Q.; Hou, C.; Wang, Z. Coupling Two Sequential Biocatalysts with Close Proximity into Metal-Organic Frameworks for Enhanced Cascade Catalysis. ACS Appl. Mater. Interfaces 2020, 12, 25565-25571, https://doi.org/10.1021/acsami.0c04317.

76. Wang, Q.; Zhang, X.; Huang, L.; Zhang, Z.; Dong, S. GOx@ZIF-8(NiPd) Nanoflower: An Artificial Enzyme System for Tandem Catalysis. Angew. Chemie 2017, 129, 16298-16301, https://doi.org/10.1002/ange.201710418.

77. Ma, W.; Jiang, Q.; Yu, P.; Yang, L.; Mao, L. Zeolitic Imidazolate Framework-Based Electrochemical Biosensor for in Vivo Electrochemical Measurements. Anal. Chem. 2013, 85, 7550-7557, https://doi.org/10.1021/ac401576u.

78. Yim, C.; Lee, H.; Lee, S.; Jeon, S. One-step immobilization of antibodies on ZIF-8/Fe3O4 hybrid nanoparticles for the immunoassay of Staphylococcus aureus. RSC Adv. 2017, 7, 1418-1422, https://doi.org/10.1039/C6RA25527B.

79. Zhang, X.; Zeng, Y.; Zheng, A.; Cai, Z.; Huang, A.; Zeng, J.; Liu, X.; Liu, J. A fluorescence based immunoassay for galectin-4 using gold nanoclusters and a composite consisting of glucose oxidase and a metal-organic framework. Microchim. Acta 2017, 184, 1933-1940, https://doi.org/10.1007/s00604-0172204-5.

80. Lyu, F.; Zhang, Y.; Zare, R.N.; Ge, J.; Liu, Z. One-Pot Synthesis of Protein-Embedded Metal-Organic Frameworks with Enhanced Biological Activities. Nano Lett. 2014, 14, 5761-5765, https://doi.org/10.1021/nl5026419.

81. Yin, Y.; Gao, C.; Xiao, Q.; Lin, G.; Lin, Z.; Cai, Z.; Yang, H. Protein-Metal Organic Framework Hybrid Composites with Intrinsic Peroxidase-like Activity as a Colorimetric Biosensing Platform. ACS Appl. Mater. Interfaces 2016, 8, 29052-29061, https://doi.org/10.1021/acsami.6b09893.

82. Zhu, G.; Cheng, L.; Qi, R.; Zhang, M.; Zhao, J.; Zhu, L.; Dong, M. A metal-organic zeolitic framework with immobilized urease for use in a tapered optical fiber urea biosensor. Microchim. Acta 2020, 187, 72, https://doi.org/10.1007/s00604-019-4026-0.

83. Zhong, C.; Lei, Z.; Huang, H.; Zhang, M.; Cai, Z.; Lin, Z. One-pot synthesis of trypsin-based magnetic metal-organic frameworks for highly efficient proteolysis. J. Mater. Chem. B 2020, 8, 4642-4647, https://doi.org/10.1039/C9TB02315A.

84. Meng, L.; Xiao, K.; Zhang, X.; Du, C.; Chen, J. A novel signal-off photoelectrochemical biosensor for M.SssI MTase activity assay based on GQDs@ZIF-8 polyhedra as signal quencher. Biosens. Bioelectron. 2020, 150, https://doi.org/10.1016/j.bios.2019.111861.

85. Bao, T.; Wen, M.; Wen, W.; Zhang, X.; Wang, S. Ultrasensitive electrochemical biosensor of interferon- 
gamma based on gold nanoclusters-graphene@zeolitic imidazolate framework-8 and layered-branched hybridization chain reaction. Sensors Actuators B Chem. 2019, 296, https://doi.org/10.1016/j.snb.2019.05.083.

86. Salgaonkar, M.; Nadar, S.S.; Rathod, V.K. Combi-metal organic framework (Combi-MOF) of $\alpha$-amylase and glucoamylase for one pot starch hydrolysis. Int. J. Biol. Macromol. 2018, 113, 464-475, https://doi.org/10.1016/j.ijbiomac.2018.02.092.

87. Bim Júnior, O.; Bedran-Russo, A.; Flor, J.B.S.; Borges, A.F.S.; Ximenes, V.F.; Frem, R.C.G.; Lisboa-Filho, P.N. Encapsulation of collagenase within biomimetically mineralized metal-organic frameworks: designing biocomposites to prevent collagen degradation. New J. Chem. 2019, 43, 1017-1024, https://doi.org/10.1039/C8NJ05246H

88. Liang, W.; Xu, H.; Carraro, F.; Maddigan, N.K.; Li, Q.; Bell, S.G.; Huang, D.M.; Tarzia, A.; Solomon, M.B.; Amenitsch, H.; Vaccari, L.; Sumby, C.J.; Falcaro, P.; Doonan, C.J. Enhanced Activity of Enzymes Encapsulated in Hydrophilic Metal-Organic Frameworks. J. Am. Chem. Soc. 2019, 141, 2348-2355, https://doi.org/10.1021/jacs.8b10302.

89. Ricco, R.; Wied, P.; Nidetzky, B.; Amenitsch, H.; Falcaro, P. Magnetically responsive horseradish peroxidase@ZIF-8 for biocatalysis. Chem. Commun. 2020, 56, 5775-5778, https://doi.org/10.1039/C9CC09358C.

90. Zhu, Q.; Zhuang, W.; Chen, Y.; Wang, Z.; Villacorta Hernandez, B.; Wu, J.; Yang, P.; Liu, D.; Zhu, C.; Ying, H.; Zhu, Z. Nano-Biocatalysts of Cyt c@ZIF-8/GO Composites with High Recyclability via a de Novo Approach. ACS Applied Materials \& Interfaces 2018, 10, 16066-16076, https://doi.org/10.1021/acsami.8b00072. 